\title{
BORGES Y LA NARRACIÓN QUE SE AUTOANALIZA
}

La mayoría de los críticos de Borges coinciden en señalar la importancia de lo literario en su obra ${ }^{1}$. Sus relatos están llenos de comentarios explícitos acerca de cómo se cuenta (lenguaje, estilo, estructura narrativa), de burlas a la retórica (a la de otros y a la suya propia) o de acotaciones en las que desmonta los engranajes de esa retórica. También suele indagar en ellos qué sentido tiene lo que se cuenta, qué relación hay entre el contar y lo contado, entre literatura y vida. Por último, no faltan los momentos de extrema tensión en los que trata de penetrar en la esencia del arte, cuando se pregunta si la literatura solo nos propone símbolos conjeturales del sentido del universo o nos coloca en el umbral de una revelación cuya magia reside en la alusión y el estremecimiento de la espera de lo que nunca se cumplirá.

Que la literatura impregnase sus relatos y además fuese asunto central de muchos de ellos, llamó pronto la atención de los lectores. En la época de Ficciones (1944) sorprendia, especialmente, un tipo de relato peculiar de esa primera etapa: el relato-ensayo. Baste recordar "El acercamiento a Almotásim", "Pierre Menard, autor del Quijote”, “Examen de la obra de Herbert Quain”, “Tres versiones de Judas". En época más tardia, la reflejada en el libro $E l$ hacedor (1960), tomó la forma de meditaciones sobre destinos de escritores y el carácter simbólico de su vida y de su-obra. Borges destacó entonces el extraño diseño que configuran -vistos sub specie aeternitatis - los sufrimientos de su vida, sus anhelos de hombres o de escritores, y la obra realizada. Pensemos en el Homero ciego de "El hacedor", en la "Parábola de Cervantes y de Quijote",

I Ramundo Lidk, en su artículo "Notas a Borges", incluido en Letras hispánicas, F.C.E., México, 1958, pp. 280-283, sugiere los múltiples caminos de la literatura ( $y$ del discurso metafísico y teológico) que se abren en sus textos. Pero aclara bien que su obra rebasa constantemente todas las fórmulas, pues "lo que vale es en definitiva ese inexplicable desbordamiento". Me perdonará que en homenaje suyo siga alguno de esos caminos sugeridos por él. 
en las revelaciones finales concedidas a Giambattista Marino en "Una rosa amarilla" o a Dante en "Inferno, I, 32" o a Shakespeare en "Everything and nothing" ".

Propia de todas las épocas y más netamente borgeana todavía es otra forma de la constante presencia de lo literario en su obra. Nos referimos al hecho de que el narrador interrumpa su relato para hacer comentarios sobre la naturaleza de la escritura. Y más aún, que ese comentario adquiera tanta importancia que se ficcionalice y acabe por convertirse en un cuento de segundo grado con respecto a la historia relatada en primer nivel.

Repasemos brevemente qué se pregunta acerca de la tarea de escribir y sus conexiones con la realidad, cuando se asoma al relato bajo las máscaras del narrador o del personaje ${ }^{3}$. A veces aparece el comentario en forma lateral, como cuando en "La espera" se nos muestra al personaje leyendo la Divina Commedia o viendo en el cine escenas de bandidos semejantes a las que él protagonizó en el Uruguay:

Vio trágicas historias del hampa; éstas, sin duda, incluían errores, éstas, sin duda, incluían imágenes que también lo eran de su vida anterior; Villari no las advirtió porque la idea de una coincidencia entre el arte y la realidad era ajena a él. [...] A diferencia de quienes han leído novelas, no se veía nunca a sí mismo como un personaje del arte $(A, 138-139)^{4}$.

La función de su comentario es muy compleja. Por una parte apunta burlonamente a los lectores que se identifican con la ficción; por otra a la fatalidad de los destinos humanos, puesto que destaca

2 También abundan en $E l$ hacedor los poemas dedicados a los destinos paradojales de otros escritores: "A un viejó poeta" [Quevedo], "A Luis de Camoens", a "Ariosto y los árabes", y aun a sí mismo ("Poema de los dones"). Hasta podría citarse el párrafo final del "Epílogo" $(H, 109)$. Es significativo que uno de sus últimos libros, escrito en colaboración con A. Bioy Casares, Crónicas de Bustos Domecq, Buenos Aires, 1967, esté dedicado integramente a las relaciones arte/vida bajo la más desaforada caricatura llevada de modo consistente hasta el extremo en la fábula y con enloquecida volubilidad en el lenguaje. Pero esa obra, por su naturaleza extrema, requiere comentario aparte.

3 Claro está que las relaciones entre literatura y universo (o entre sueño y vida, imagen y objeto, etc.) pueden interpretarse como incluidas en la más abarcadora de realidad e irrealidad, que he desarrollado en mi libro La expresión de la irrealidad en la obra de Jorge Luis Borges, México, 1957 (2a ed. Buenos Aires, 1967). En este trabajo me limito a su manifestación en el comentario del narrador.

4 Cito por las siguientes ediciones de las Obras completas, Emecé, Buenos Aires, con la sigla indicada entre paréntesis Ficciones $(F), 1956 ; \mathrm{El}$ Aleph $(A)$, 1957; El hacedor $(H), 1960 ;$ Otras inquisiciones $(O I)$, 1960; El inforne de Brodic $(B), 1970$. 
la ceguera del personaje ante los anuncios premonitorios de la muerte ${ }^{5}$; por otra a la intercambiabilidad simbólica de vida y literatura, y aun a la neutralización de la oposición simbólico/nosimbólico. En efecto un cuento que es símbolo de destinos humanos lleva en sí la negación de su capacidad de ser símbolo.

Otro ejemplo quizás más sorprendente y más borgeano aún lo constituyen las breves líneas que el narrador intercala como comentario informativo en el cuento "El hacedor", refiriéndose al momento en que Homero se queda ciego: "Cuando supo que se estaba quedando ciego, gritó; el pudor estoico no había sido aún inventado y Héctor podía huir sin desmedro" $(H, 10)^{6}$.

Por boca del narrador se destaca que ciertos rasgos de verosimilitud psicológica (atribuir a un personaje excepcional el estallido instintivo de su dolor o a un héroe la fuga) son tradiciones literarias cronológicamente identificables, es decir que son hechos convencionales y no rasgos debidos a la copia fiel de la vida. Pero al insinuar irónicamente que el pudor estoico es un tipo de conducta creado por la literatura, se sugiere que una construcción del arte puede revertir sobre la realidad y crear un modelo de comportamiento para los hombres. A esto se agrega el que el ejemplo elegido (Héctor) está tomado de una obra escrita por el protagonista (Homero) cuyo destino se comenta, pero se lo menciona aludiendo a un momento de su vida en que todavía no la había redactado ${ }^{7}$. Además siempre se juega con la doble naturaleza de Héctor y de Homero, seres con posible existencia histórica (vida) o simples configuraciones imaginarias, puesto que fueron moldeados como arquetipo del Héroe por la tradición épica y como arquetipo del Vate por la tradición de los comentaristas.

En los pasajes antes citados, las observaciones constituyen inserciones momentáneas en el decurso narrativo. En otras circunstancias, Borges destaca posicionalmente sus preocupaciones por la

5 Hay en esta actitud algo de la tradicional "ironía trágica"; lo característico de Borges es que las señales que el personaje rechaza son de tipo literario y su negación incluye recursivamente la negación del relato y de su misma naturaleza.

6 Los datos con que construye su vida de Homero están conscientemente tomados de la tradición más común del aedo ciego: existencia de un solo autor creador de la-Itiada y la Odisea, patetismo del contraste entre su ceguera física y su videncia poética.

T Estas inclusiones suelen atraer a Borges, pero nunca en forma mecánica sino con sutiles variantes. Recuérdese el caso del narrador en "La biblioteca de Babel", que conjetura que su relato debe figurar también en la Biblioteca (puesto que ella es total), lo cual desata una infinita recursión $(F, 94)$; y la nota $1(\mathcal{F}, 95)$ del mismo cuento, que propone otra sustancia narrativa para la forma encarnada en dicha ficción, pero es además una nueva versión de las aporías de Zenón de Elea, que tanta fascinación ejercen sobre Borges. 
relación texto/extra-texto; pueden ir como introducción o al final o en ambas posiciones, enmarcando la ficción.

En "La busca de Averroes" cuenta primero el fracaso del protagonista, que intenta en vano explicarse la Poética de Aristóteles, y acaba con este comentario puesto explícitamente en boca del "autor".

En la historia anterior quise narrar el proceso de una derrota. Pensé, primero, en aquel arzobispo de Canterbury que se propuso demostrar que hay un Dios; luego, en los alquimistas que buscaron la piedra filosofal; luego en los vanos trisectores del ángulo y rectificadores del círculo. Reflexioné, después, que más poético es el caso de un hombre que se propone un fin que no está vedado a los otros, pero sí a él. Recordé a Averroes, que, encerrado en el ámbito del Islam, nunca pudo saber el significado de las voces tragedia y comedia. Referí el caso; a medida que adelantaba, sentí lo que hubo de sentir aquel dios mencionado por Burton que se propuso crear un toro y creó un búfalo. Sentí que la obra se burlaba de mí. Sentí que Averroes queriendo imaginar lo que es un drama sin haber sospechado lo que es un teatro, no era más absurdo que yo. queriendo imaginar a Averroes, sin otro material que unos adarmes de Renan, de Lane y de Asín Palacios. Sentí, en la última página, que mi narración era un símbolo del hombre que yo fui, mientras la escribía y que, para redactar esa narración, yo tuve que ser aquel hombre y que, para ser aquel hombre, yo tuve que redactar esa narración, y así hasta lo infinito. (En el instante en que yo dejo de creer en él, "Averroes" desaparece) $[A, 101]$.

Borges -autor del relato- se elige a si mismo como máscara del "escritor", se ficcionaliza y se presenta en el proceso de invención de un relato: pensando primero en su forma genérica (fracaso) y en las posibles sustancias narrativas para esa forma (prueba de la existencia de Dios...., etc.) y eligiendo luego la más adecuada, nótese que por ser la más poética.

Llama la atención que este proceso presenta bajo el aspecto de engendramiento diacrónico de un cuento (serie de etapas cronológicas en su concretización como texto), un diseño similar a los finales de otros relatos. Es muy usual en Borges (en el Borges de Ficciones, de El Aleph o de los ensayos de Otras inquisiciones) el presentar primero una historia extraña y "verdadera" (por ejemplo "La otra muerte") y desplegar al final un abanico de hipótesis explicativas, entre las cuales, a vèces, se privilegia una. En "La busca de Averroes", aunque la fórmula no se presenta como hipótesis explicativas sino como descripción de su engendramiento diacrónico y aunque no parte de un relato concreto sino de un núcleo 
semántico en su mayor grado de generalidad (fracaso), también se proponen varias alternativas y se elige una ${ }^{8}$.

En el nivel de la producción literaria, cada una de esas propuestas es un embrión de otros tantos relatos posibles. Para el caso de "La busca de Averroes" son relatos potenciales como escritura que existen paralelamente al relato realizado; para el de "La otra muerte", son potenciales lecturas de un texto que existe como escritura única. En ambas situaciones, la proyección de unos fantasmas sobre los otros invita a practicar una lectura múltiple y compleja.

Hecho este paréntesis, volvamos al fragmento antes citado por extenso. Al llegar a ese punto se ilumina con un primer plano de brillo inusitado su carácter simbólico y se refuerza el patetismo y la ironía al revertir las consecuencias en forma cíclica infinita sobre la obra, sobre el autor del relato (sobre cualquier autor) y sobre el propio lector 9 . "Algebra y fuego", formas eternas y humanidad concreta. El abanico de los otros posibles relatos no ha sido en vano, porque ha llevado al extremo la tensión del destino del protagonista al realzar la inevitabilidad del fracaso (que no depende de él ni de su voluntad sino del azar de las circunstancias), y además su vacuidad (dada la intercambiabilidad de los sujetos). Es decir que en el mismo momento en que lo borra como persona ("en el instante en que yo dejo de creer en él, «Averroes» desaparece"), en' el mismo momento en que lo erige en símbolo, nos lo acerca por las debilidades de su condición humana compartidas ("el hombre que yo fui") .

En realidad no parece demasiado arbitrario decir que Borges, en la mayoría de sus cuentos, construye un objeto simbólico a través de una historia personalizada. La naturaleza trópica de sus relatos ha sido destacada por los críticos y por el mismo autor.

En "La busca de Averroes" se trasmite una historia concreta y se la eleva luego a símbolo. En el "Tema del traidor y del héroe" se comienza procediendo a la inversa, como lo sugiere la alusión a Chesterton y Leibniz. Se parte del topos de "el gran teatro del mundo", forma simbólica acuñada por la tradición literaria, y se ficcionaliza su conversión en una supuesta "realidad" dentro del orbe cerrado de la obra, para reconvertirlo al final en el topos que lo generó. En efecto, los hechos narrados postulan que para casti-

$s$ Véase algo similar en el comienzo de "Tema del traidor y del héroe" que analizamos más adelante.

9 Ironía no solo en que la obra denuncie el vano empeño de su creador, sino en que el mismo autor descubra la trampa que hay en la recreación del Islam (Lane, Renan, Asín Palacios) y en toda recreación. Decimos que alcanza al lector porque le muestra que prestó su adhesión a un simulacro construido con tan pobres materiales. Sin embargo, la burla oculta quizás una soberbia o por lo menos una velada apología del arte bajo su detracción. 
gar al héroe-traidor y no escandalizar a sus seguidores, se ha escrito un drama que el protagonista, la ciudad entera y aun el historiador posterior repetirán de acuerdo con los papeles propuestos.

El cuento no es únicamente una fabulación moderna - no teológica- del gran teatro del mundo; no es solo un símbolo del hombre que se piensa libre y es un autómata con destino prefijado. Es además -entre otras muchas cosas- la cristalización de una forma "eterna y secreta": la unidad última de los opuestos, la conciliación de los contrarios. Así lo destaca el título elegido "Tema del traidor y del héroe", que subraya su naturaleza arquetípica ${ }^{10}$.

La atención de Borges va dirigida cada vez más a buscar bajo las aparentes particularidades y diferencias las relaciones generales y abarcadoras. Quizás porque de ese modo impone un simulacro de orden en la caótica realidad y oblitera la historia. Teoría y práctica resultan así esencialmente fieles una a la otra. No olvidemos que para Borges el arte existe como acuñación de formas elementales que sean capaces de conmover a todos los hombres, que sean "todo para todos, como el Apóstol" (OI, 259) ${ }^{11}$.

Por eso a veces el narrador destaca que el interés de la anécdota reside en su carácter simbólico. A propósito de "La intrusa" dice: "La escribo ahora porque en ella se cifra, si no me engaño, un breve y trágico cristal de la índole de los orilleros antiguos" $(B, 15)$.

Ya volveremos más adelante sobre este rasgo tan borgeano, para integrarlo en la totalidad de su conducta narrativa, que trataremos a continuación.

Cuando se postula que los acontecimientos son "reales", no llama la atención que el relator asegure su veracidad y declare los hechos que la avalan. Tampoco que afirme su intento de no tergiversarlos y de transcribirlos con la mayor fidelidad. Este proceder ha sido tradicional en los relatos llamados realistas pero aún más en los fantásticos, que apuntalan la inverosimilitud de los hechos con una profesión de fe de objetividad.

Más extraños a la tradición literaria son otros comportamientos muy típicos de Borges. Uno es el que denuncia el seguro falseayुgyos.

10 Uno de los rasgos salientes del cuento es la presentación de todo ese proceso (forma eterna-topos-"realidad"-forma eterna) a través de un relato de primer nivel que consiste en ficcionalizar la tarea del futuro narrador (el historiador de los hechos) en su apasionada búsqueda, casi policial, de la verdad histórica.

11 Véanse por ejemplo los ensayos de Otras inquisiciones que dedica a las formas eternas y a las imágenes, o aquellos en que teoriza sobre las alegorías. En su "Epílogo" descubre su tendencia "a presuponer (y verificar) que el número de fábulas o de metáforas de que es capaz la imaginación es limitado" $(O I, 259)$, pero que su valor es esencial. 
miento de los hechos por arrastre retórico. En "La intrusa” el narrador aclara acerca de su modo de relatar: "Lo haré con probidad, pero ya preveo que cederé a la tentación literaria de acentuar o agregar algún pormenor" $(B, 15)$. Después de haber postulado la historicidad de los hechos, recuerda inmediatamente que la elaboración retórica acompaña todo ejercicio literario y no puede ocurrir de otro modo por su misma naturaleza.

En "El indigno" bajo la voz del personaje-narrador se burla de sí mismo al burlarse de su oyente ficticio al que ha hecho asumir la máscara de Borges-escritor: "Voy a revelarle una cosa que no he contado a nadie [...]. A lo mejor le sirve para un cuento, que usted, sin duda, surtirá de puñales" $(B, 26)$. La ironía de estas líneas abarca a cualquier escritor afecto al color local y revierte sobre Borges, al que el lector conoce como aficionado a los relatos de malevos y como crítico de su propia literatura juvenil cargada de pintoresquismos ${ }^{12}$. Más fina alusión a la elaboración especial a que está sometida la materia literaria, cualquiera que sea su origen, es el párrafo inicial de "El duelo":

Henry James - cuya labor me fue revelada por una de mis dos protagonistas, la señora de Figueroa- quizás no hubiera desdeñado la historia. Le hubiera consagrado más de cien páginas de ironía y ternura, exornadas de diálogos complejos y escrupulosamente ambiguos. No es improbable su adición de algún rasgo melodramático. Lo esencial no habría sido modificado por el escenario distinto: Londres o Boston. Los hechos ocurrieron en Buenos Aires y ahí los dejaré. Me limitaré a un resumen del caso, ya que su lenta evolución y su ámbito mundano son ajenos a mis hábitos literarios $(B, 89)$.

En esta introducción se nos anuncia el relato de unos acontecimientos y simultáneamente la posibilidad de que haya varias maneras de contarlos, enfrentando la de Henry James a la del narrador-autor. En la descripción y preferencias de rasgos de estilo, el lector reconoce para este último, el perfil de Borges, y admira la síntesis descriptiva del arte de Henry James, el comprensivo humor de quien se siente ligado a él por "simpatías y diferencias". En un texto tan concentrado -pero que compite en ambigüedad con Henry James- se multiplican los reflejos especulares de literatura y vida. Primero postula como real una historia inventada, para

12 Recuérdese que al reeditar sus poemas juveniles los ha sometido a constantes correcciones para eliminarlos; también es significativo que en El informe de Brodie incluya, bajo el título de "Historia de Rosendo Juárez", una nueva versión de la fábula contada en "Hombre de la esquina rosada", que responde a la misma actitud ante el lenguaje y también ante la imagen del hombre del suburbio, moderadora del exceso pintoresquista. 
luego pasarla al plano de lo literario por el hipotético atractivo que ejercería sobre un autor conocido, dada su naturaleza. Esto nos obliga a atribuir al "hecho real" la configuración jamesiana de su "lenta evolución y su ámbito mundano", y la lectura del breve relato ("un resumen") se carga de alusión a lo supuestamente omitido y sus complejos laberintos ${ }^{13}$. En vez de ser la mimesis de la vida, será un simulacro de un simulacro (como le gustaría decir a Borges, recordando a Platón) lo que irónicamente se nos conceda.

Otro de los rasgos más constantes de la retórica borgeana es el desarrollo narrativo de tipo lacunar. La historia suele figurar como una cadena de hechos de los que sólo se han podido o se han querido salvar unos eslabones. No incluye, pues, toda la rica, compleja (quizás tediosa), sin duda inabarcable e infinita sucesión de momentos que la compusieron. No solo procede el escritor por saltos y por informaciones fragmentarias (eso es al fin lo que hacen todos, aun los más detallistas). Lo peculiar de Borges es que se toma el trabajo de llamar la atención sobre ese fragmentarismo. De la "Biografía de Tadeo Isidoro Cruz" acota: "En su oscura y valerosa historia abundan los hiatos" $(A, 55)$.

Los hiatos de las ficciones pueden aparecer justificados porque la memoria olvida, simplifica, falsea, empobrece o embellece, pero de todos modos tiene una forma azarosa, a veces significativa, de reducir la riqueza de la vida. También porque escribir es inventar o reelaborar esos datos, y la selección diseña una construcción de sentido, un orden impuesto por la obra de arte, mientras la caótica realidad sigue su curso. También porque, planteado el problema en forma absoluta, es imposible la transcripción de un universo infinito (para no hablar de los problemas que propone el código de signos usado en esa transcripción, y su relación con el referente $\left.{ }^{14}\right)$. También porque hay misterios en la vida de los hombres que nunca les fueron revelados, que quedan más allá del conocimiento de la gente que los vivió, del cronista de la historia, o de cualquier conocimiento humano.

Si nos fijamos bien en esta conducta narrativa, nos damos cuenta de que Borges es el creador de una retórica nueva, de una retó-

13 Notemos que en este relato vuelve a jugar con la relación literatura vida bajo la idea de que sea la protagonista de un cuento que le hubiera gustado contar a H. James, la que introduzca a su "autor" en el conocimiento del escritor $\mathbf{H}$. James.

14 La dimensión metafísica de este tópico aflora en cuentos, ensayos y poe. mas. Baste recordar para la enumeración de un conjunto infinito "El Aleph" $(A, 164)$, para la trasmisión por el lenguaje de experiencias no compartidas, dicho cuento y "La busca de Averroes" ( $A$, 163 y 95-96), para código y referente infinitos "Funes el memorioso" $(F)$. Véase también el párrafo del "Prólogo" a El informe de Brodie que citamos más adelante $(B, 7)$. 
rica personal de la verosimilitud que le es necesaria por la especial naturaleza de su arte.

Su retórica da ciertos detalles mínimos de "realidad" para sostener una obra que se caracteriza muchas veces por moverse en el ámbito de lo fantástico y casi siempre con una carga simbólica. Por una parte practica la personalización parcial de sus héroes ${ }^{15}$ y la concretización también parcial de algunas aventuras. Pero por otra desnuda a los personajes y a las acciones de su particularidad hasta marcar su condición de elementos que dibujan formas secretas y eternas. El comentario constante de las voces narrativas en juego oscilante entre mimesis e invención acompaña este proceso, que muchas veces se aventura al peligroso extremo de explicitar dónde reside su capacidad simbólica y qué forma universal y abstracta propone. Es decir que el esquematismo, los hiatos, el realce de ese nudo central serían los instrumentos retóricos que fingen transformar una "realidad" en símbolo, porque hacen suponer que ese proceso se ha producido por despojamiento de la rica experiencia vital en su esencia arquetípica, postulando la existencia de ese mundo' concreto y múltiple que es su soporte. (No olvidemos que también nos acostumbran a la peligrosa reversibilidad de esos ámbitos, que se separa para poder unirlos y se une para poder separarlos).

Los textos suelen figurar como fórmulas provisorias de las cuales aún no se conocen ciertos detalles o que tienen ciertas lagunas ("ignoro los detalles de su aventura; cuando me sean revelados he de rectificar y ampliar estas páginas. Por ahora este resumen puede ser útil" dice en "El muerto", $A, 27$ ). También ofrece indicaciones de que no se trascribe más que una parte de esa rica existencia ("Aquí la historia se complica y se ahonda. [...] Muchas cosas van aconteciendo después, de las que sé unas pocas", $A, 32$ ). O propone versiones contradictorias de un mismo hecho (“... esa tarde Otálora regresa al Suspiro en el colorado del jefe y esa tarde unas gotas de su sangre manchan la piel de tigre y esa noche duerme con la mujer de pelo reluciente. Otras versiones cambian el orden de estos hechos y niegan que hayan ocurrido en un solo día", $A$, 32). La cronología de los acontecimientos no interesa, dado que no afecta su papel simbólico. Además, la segunda versión alude, por contraste con la primera, a la naturaleza del arte como artificio y, al desnudar el procedimiento de concentrar en un día la adquisición de los atributos del poder, vuelve a subrayar su condición alegórica.

Paralelamente a esto, los narradores insisten en advertirnos que

15 Sylvia Molloy, en conferencia pronunciada en Columbia University en 1973 (aún no publicada), desarrolló penetrantemente esta característica de Borges en la presentación de los personajes. 
hay un núcleo de los acontecimientos que encierra todo el sentido del texto. Unas veces, después de callar unos hechos y de pasar rápidamente por otros, cargan la tensión en uno para realzar su función de clave de los destinos humanos.

(Lo esperaba, secreta en el porvenir, una lúcida noche fundamental: la noche en que por fin vio su propia cara, la noche en que por fin escuchó su nombre. Bien entendida, esa noche agota su historia; mejor dicho, un instante de esa noche, un acto de esa noche, porque los actos son nuestro símbolo). Cualquier destino, por largo y complicado que sea, consta en realidad de un solo momento: el momento en que el hombre sabe para siempre quién es $(A, 55)$.

Postulada la "realidad" de lo narrado (la existencia del referente externo), la vida adquiere la naturaleza del lenguaje y de la literatura: unos objetos son "adjetivos" o "atributos" de otros, unos hechos pueden funcionar como significantes de otros ${ }^{16}$ (es decir, sugerir un significado central y a la vez irradiante).

En otras ficciones, expone circunstancias variadas pero declara que el relato tiene un núcleo semántico que puede quedar oscurecido por incidentes sólo importantes en apariencia: "Lo esencial de la historia que le refiero es mi relación con Ferrari, no los sórdidos hechos de los que ahora no me arrepiento". Dice el narrador de "El indigno" $(B, 31)$. Así obliga a la relectura de una historia concreta de delación y de malevos, realizada en otra clave, para descubrir una forma secreta: la eterna lucha del hijo que mata al padre ${ }^{17}$.

Más destacada aún resulta esta conducta narrativa que consideramos como una nueva retórica de la verosimilitud, en los cuentos en que el narrador confiesa manejar una materia imaginada por él. Por ejemplo, recordemos cómo se inicia "Tema del traidor y del héroe":

Bajo el notorio influjo de Chesterton (discurridor y exornador de elegantes misterios) y del consejero áulico Leibniz (que inventó la armonía preestablecida), he imaginado este argumento, que escribiré tal vez y que ya de algún modo me justifica, en las tardes inútiles $(F, 137)$.

16 Para la función simbólica de los acontecimientos y para el léxico que alude a dicha función, véase mi libro antes citado, $2^{a}$ ed., pp. 82-101.

$17 \mathrm{La}$ misma forma del duelo eterno aparece como: el héroe vendido por el amigo ("La forma de la espada", $F$, 129), el protector asesinado por el protegido ("La trama", $H, 28$ ), y otras asume la imagen de una lucha en la que víctima y victimario tienden a unificarse ("Los teólogos", $A, 35 ;$ " El duelo" y "Guayaquil", $B, 87$ y 109, y "El fin", $F, 177$ ), para citar solo unos ejemplos. 
Después de un planteo tan desembozado de la autonomía del texto con respecto a su referente externo, unido a la alusión indirecta de su carácter simbólico, ficcionaliza las etapas sucesivas de su creación. El cuento ofrece un esbozo de desarrollo diacrónico generador, algo similar al que ya analizamos en "La busca de Averroes". La primera etapa lo muestra configurado sólo en líneas provisionales, aún no determinado el lugar ni la época: "Faltan pormenores, rectificaciones, ajustes; hay zonas de la historia que no me fueron reveladas aún; hoy, 3 de enero de 1944, lo vislumbro así: La acción transcurre en un país oprimido y tenaz: Polonia, Irlanda, la república de Venecia, algún estado sudamericano o balcánico..."

Enseguida se precisa el tiempo de la narración (el narrar), aunque no todavía el hiato exacto que lo separa de lo narrado: "Ha transcurrido, mejor dicho, pues aunque el narrador es contemporáneo, la historia referida por él ocurrió al promediar o al empezar el siglo XIx".

Inmediatamente se acelera el proceso de configuración fijando el tiempo, el lugar, y los caracteres del narrador y del héroe: "Digamos (para comodidad narrativa) Irlanda; digamos 1824. El narrador se llama Ryan; es bisnieto del joven, del heroico, del bello, del asesinado Fergus Kilpatrick, ..." Notemos, de paso, que si el proceso de la creación aparece en algunas líneas como misterioso e incontrolable ("hay zonas de la historia que no me fueron reveladas aún" 1.8), en otras figura como elección consciente aunque parcialmente arbitraria ("digamos por comodidad narrativa"), quizás aludiendo a que por tratarse de una forma, las sustancias (Hjelmslev) pueden ser intercambiadas sin afectar el diseño ("un dibujo de líneas que se repiten").

En su sistema de relato explícitamente lacunar, el responsable de la historia puede destacar un no-saber imposible de superar. De la breve biografía de Homero rescatada en "El hacedor", conoce hechos que recomponen una vida dedicada a la fruición directa, algunos tan peculiares como "el sabor de la carne de jabalí, que le gustaba desgarrar con dentelladas blancas y bruscas", para aludir a un ámbito de vida primitiva. Destaca dos recuerdos capitales cuando se queda ciego, su iniciación en "el amor y el riesgo", que se proyectan en la futura creación de la Iliada y la Odisea. Después concluye así: "Sabemos estas cosas pero no las que sintió al des-

18 La frase funciona para dar patetismo al destino del hombre, pero corresponde también a una imagen del autor como mero amanuense de la Divinidad, que es recurrente en Borges y que a su vez se conecta con su concepto de la literatura como obra de un autor universal (encontrado en Valery) y con la visión panteista y la tendencia a resolver la pluralidad en la unidad. 
cender a la última sombra" $(H, 11)$. Y lo que no se sabe es el enigma más allá de la muerte: vacío simbólico o plenitud simbólica, sentido secreto sugerido pero no explicitado o explicitación de que nunca se conocerá el secreto o remisión de la clave a la Divinidad, lo que es otra forma de negársela al hombre. Detención del narrador en el umbral intraspasable o en el momento en que la revelación está por configurarse. No en vano Borges definió así el hecho estético:

Generalizando el caso anterior, podríamos inferir que todas las formas tienen su virtud en sí mismas y no en un "contenido" conjetura. [...] La música, los estados de felicidad, la mitología, las caras trabajadas por el tiempo, ciertos crepúsculos y ciertos lugares, quieren decirnos algo, o algo dijeron que no hubiéramos debido perder, o están por decir algo: esta inminencia de una revelación, que no se produce, es quizá, el hecho estético $(O I, 12)$.

A través de nuestro comentario hemos visto una narratividad que no deja de analizarse a sí misma, una retórica que no deja de hablar de su naturaleza retórica: en síntesis, un texto que no deja de aludir a su condición de texto. Eso implica la existencia de un extra-texto con el cual el texto mantiene relaciones ambiguas, paradójicamente polares e intercambiables. Tales relaciones se entienden mejor si pensamos que Borges construye narraciones simbólicas que quieren mantener cierta ilusión de "realidad" sin dejar de apuntar a su esencia arquetípica, recordándonos siempre que literatura y vida son dos orbes cerrados y ajenos, aunque a veces se goce con interpolar uno en el otro. Lo único que los conecta es, por una parte, que la vida adquiera el funcionamiento del lenguaje (acontecimientos-símbolos, naturaleza-libro, vida-teatro) y, por otra, que la literatura y el lenguaje impliquen la existencia del universo, a pesar de su heterogeneidad. En el Prólogo a $\mathrm{El} \mathrm{in-}$ forme de Brodie dice de sus cuentos: "No me atrevo a afirmar que son sencillos: no hay en la tierra una sola página, una sola palabra, que lo sea, ya que todas postulan el universo, cuyo más notorio atributo es la complejidad" $(B, 7)$.

$\mathrm{Si}$ su tarea de escritor reside, según Borges, en la construcción de símbolos, estos no necesitan ser -insistamos- develadores de lo real, basta con que sean todo para todos, que creen un lugar donde los hombres puedan reconocerse.

Por fascinantes que nos parezcan (lectores saturados de literatura), todos sabemos qué quieren decir ese platonismo, ese panteísmo, ese universalismo en el siglo $\mathrm{xx}$, ese texto que vuelve incesantemente sobre sí, ese refugio del hombre en el mundo de los sueños como hacedor de mitos, junto a la absoluta obliteración de la historia y del hombre como hacedor de su propia historia. No 
hay un lugar para todos los hombres. La increíble lucidez de Borges en la deconstrucción de pre-conceptos, de ideas recibidas, y de estilos (solo comparable a su increíble miopía socio-histórica) se detiene ante deconstrucciones de otro tipo que socavarían sus arquetipos. Sin embargo la ambigüedad, las paradojas y las tensiones que subyacen en su orbe literario apuntan, aun a su pesar, a esa deconstrucción.

Ana María Barrenechea

Columbia University. 